\title{
A OPERACIONALIZAÇÃO DO MERCADO INSTITUCIONAL DE ALIMENTOS NO CONTEXTO DO VALE DO RIO PARDO-RS
}

\section{INSTITUTIONAL FOOD MARKET OPERATION IN THE CONTEXT OF THE VALE DO RIO PARDO-RS}

\author{
Antônio Carlos Gomes \\ Escola Família Agrícola de Santa Cruz do Sul - Santa Cruz do Sul - RS - Brasil \\ Cidonea Machado Deponti \\ Universidade de Santa Cruz do Sul - Santa Cruz do Sul - RS - Brasil
}

\begin{abstract}
Resumo: O presente estudo tem como objetivo analisar a construção do mercado institucional de alimentos no contexto do Vale do Rio Pardo, por meio de um estudo de caso da Cooperativa Leoboqueirense de Agricultores Familiares - COOPERLAF. O ponto de partida é a existência consolidada e predominante da cadeia produtiva do tabaco nesta região, o que implica avaliar o mercado institucional de alimentos - por meio do Programa de Aquisição de Alimentos - PAA e do Programa Nacional da Alimentação Escolar - PNAE - enquanto possibilidade concreta de diversificação da produção da agricultura familiar e de conquista de autonomia por parte dos agricultores. Constata-se que a inserção dos agricultores familiares no mercado institucional de alimentos por meio da COOPERLAF está possibilitando a abertura de novos canais de comercialização e geração de renda, diminuindo o seu nível de dependência em relação à produção de tabaco. Assim, sob a perspectiva conceitual da recampesinização, sugere-se que as políticas públicas de Segurança Alimentar e Nutricional - SAN representam a oportunidade de um desenvolvimento regional de caráter endógeno e, portanto, sustentável no Vale do Rio Pardo, a partir da valorização da agricultura familiar enquanto produtora de alimentos saudáveis.
\end{abstract}

Palavras Chave: Agricultura Familiar. Mercado Institucional de Alimentos. Segurança Alimentar e Nutricional. Vale do Rio Pardo recampesinização.

Abstract: This study aims to analyze the operation of institutional food market in the context of Vale do Rio Pardo, through a case study of the Cooperativa Leoboqueirense de Agricultores Familiares - COOPERLAF. The starting point is the consolidated and predominant presence of the tobacco supply chain in this region, which involves 
consider the institutional food market (through the PAA and the PNAE) as a concrete possibility of productive diversification of family farming. It appears that the inclusion of family farmers in institutional food market through COOPERLAF is enabling the opening of new sales channels and income generation, reducing the dependency level in relation to tobacco production. Thus, from a conceptual perspective of repeasantization, it is suggested that the SAN public policies represent the opportunity for an endogenous regional development and, therefore, sustainable, in the Vale do Rio Pardo, based on the value of family farming as healthy food producers.

Key words: Family Farm. Institutional Food Market. Food and Nutrition Security. Vale do Rio Pardo repeasantization.

\section{INTRODUÇÃO}

A agricultura familiar tem sido pauta das políticas públicas brasileiras nos últimos anos e, especificamente, a partir da emergência do conceito de SAN, passou a fazer parte de uma estratégia de combate à fome e também de desenvolvimento do país. A criação do PAA e a evolução do PNAE tornaram a agricultura familiar um elemento fundamental na busca pela aproximação entre produção e consumo de alimentos, visando garantir o acesso à alimentação saudável a famílias em situação de vulnerabilidade social.

Dessa forma, além de facilitar o acesso ao alimento, os programas de SAN visam incentivar a diversificação produtiva por meio de mecanismos que conectam a oferta da produção familiar a uma demanda garantida e permanente. Trazem, em seus objetivos, o desafio de fortalecer os circuitos locais e regionais $e$ as redes de comercialização; valorizam a biodiversidade e a produção orgânica e agroecológica de alimentos; incentivam hábitos alimentares saudáveis e estimulam o associativismo.

Contudo, o desafio maior desses programas está no contraponto estabelecido ao modelo agrícola baseado em uma agricultura especializada, dependente de insumos e de agrotóxicos e voltada à produção de commodities'. A partir do conceito de SAN, essas políticas públicas pretendem substituir o incentivo dado às grandes cadeias integradas, à produção agrícola monocultora e aos grandes

'Commodities: São as mercadorias negociáveis no mercado internacional. Podem ser commodities alimentícias, como bebidas e cereais, ou não alimentícias, como algodão e tabaco (HELENE; MARCONDES; NUNES, 1994, p. 5). 
conglomerados multinacionais de industrialização e de comercialização de alimentos, pela prioridade à produção da agricultura familiar ou dos pequenos e dos médios empreendimentos (MALUF, 2011).

Por isso, considerando a diversidade de expressões da agricultura familiar no Brasil (SCHNEIDER, 2006), especialmente em relação ao seu maior ou menor grau de integração ao mercado, bem como os inúmeros arranjos regionais que influenciam diretamente na forma de execução das políticas públicas, não serão demasiados os estudos que permitam compreender como os SANs (PAA e PNAE) repercutem em cada realidade específica.

Nesses termos, a agricultura familiar do Vale do Rio Pardo e sua profunda integração com a rede agroindustrial do tabaco constitui-se em um foco importante de estudo. A característica particular dessa região, dentre outras no Sul do Brasil, é a presença do Sistema Integrado de Produção de Tabaco - SIPT que vem sendo desenvolvido há quase um século. Por meio desse sistema, as empresas (transnacionais) beneficiadoras do tabaco realizam contratos com os agricultores familiares, oferecendo um pacote tecnológico composto por sementes, insumos, assistência técnica especializada e garantia de compra de toda a produção.

As consequências socioeconômicas desse sistema são controversas. Como aponta Vargas (2013), existem evidências dos efeitos nocivos do controle exercido pela indústria do fumo sobre a organização da cadeia agroindustrial do tabaco nos países em desenvolvimento. No caso do Vale do Rio Pardo, pode-se destacar, inicialmente, a dependência econômica gerada por esse sistema, na medida em que a economia dos municípios encontra-se amplamente alicerçada sobre a produção do tabaco. A participação do tabaco no Valor Bruto da Produção - VBP agrícola dos municípios do Vale do Rio Pardo é, em média, de 61,5\% (IGBE, 2010).

Assim, diante da emergência dos programas de SANs, especificamente o mercado institucional de alimentos representado pelo PAA e o PNAE, e da complexa realidade da agricultura familiar no Vale do Rio Pardo, surge o objetivo central desta pesquisa: analisar a operacionalização do mercado institucional de alimentos no contexto do Vale do Rio Pardo. 
Definiu-se como estudo de caso a COOPERLAF, localizada no Município de Boqueirão do Leão, por ser uma das poucas e, provavelmente, a pioneira entre as cooperativas de agricultores familiares existentes nos 23 municípios da região que comercializam produtos por meio dos programas PAA e PNAE. Fundada em dezembro de 2010, a COOPERLAF é uma cooperativa relativamente pequena, formada atualmente por 41 sócios, e tem atuação focada no âmbito de seu município-sede e arredores. Mas sua experiência desperta atenção, já que Boqueirão do Leão é o município do Vale do Rio Pardo em que o tabaco possui a maior participação no VBP agrícola, que é de $91,67 \%$ (IBGE, 2010) e, portanto, um município onde a condição de dependência em relação ao tabaco é bastante expressiva.

\section{UM OLHAR “REGIONAL” SOBRE O VALE DO RIO PARDO}

Parte-se do conceito de que uma "região" consiste em um espaço dinâmico, construído e vivenciado entre o local e o global, ou seja, uma "mediação entre o universal (processos gerais advindos da globalização) e o singular (a especificação máxima do universal)" (CORRÊA, 1997, p. 192). Dessa forma, justifica-se a opção deste estudo pelo recorte regional do Conselho Regional de Desenvolvimento - Corede ${ }^{2}$, justamente por sua vinculação aos processos contemporâneos de planejamento e de desenvolvimento regionals.

\footnotetext{
${ }^{2}$ Criados pela Lei $\mathrm{n}^{\circ} 10.283$, de 17 de outubro de 1994, os Coredes têm por objetivo a promoção do desenvolvimento regional, harmônico e sustentável, através da integração dos recursos e das ações de governo na região, visando à melhoria da qualidade de vida da população, à distribuição equitativa da riqueza produzida, ao estímulo à permanência do homem em sua região e à preservação e recuperação do meio ambiente. Os municípios que integram a Região do Vale do Rio Pardo são: Arroio do Tigre, Boqueirão do Leão, Candelária, Encruzilhada do Sul, Estrela Velha, General Câmara, Herveiras, Ibarama, Lagoa Bonita do Sul, Mato Leitão, Pantano Grande, Passa Sete, Passo do Sobrado, Rio Pardo, Santa Cruz do Sul, Segredo, Sinimbu, Sobradinho, Tunas, Vale do Sol, Vale Verde, Venâncio Aires e Vera Cruz.

3 Como afirma Bandeira (2013), a atuação dos Coredes/RS, ao promover a articulação e mobilização dos atores sociais e econômicos das regiões do Rio Grande do Sul para a promoção do desenvolvimento, tornando possível que esses atores interajam de forma organizada com as instâncias governamentais, contribui de forma decisiva para viabilizar ações que se enquadram na concepção de um novo paradigma do desenvolvimento regional. Diferente da abordagem tradicional, baseada quase exclusivamente em incentivos fiscais e financeiros às empresas e sendo gerida apenas
} 
O Corede do Vale do Rio Pardo congrega 23 municípios localizados na região central do Rio Grande do Sul e tem como característica comum a predominância de áreas rurais, a baixa taxa de urbanização e a predominância da agricultura familiar vinculada ao SIPT. Seguindo os critérios do Instituto Brasileiro de Geografia e Estatística IBGE (2010), constata-se que apenas 2,03\% do território do Vale do Rio Pardo é considerado urbano ${ }^{4}$, tendo uma taxa de urbanização média de $63,12 \%$, bem abaixo da média estadual do Rio Grande do Sul, que é de $85,1 \%$ (IBGE, 2010). Além disso, os números do Censo Agropecuário (2006) do IBGE apontam que a área ocupada pelos estabelecimentos da agricultura familiar nessa região corresponde a 64,55\% das terras, enquanto que no Estado do Rio Grande do Sul esse número é de apenas $30,3 \%$. A mesma diferença se observa em relação à região Sul, que tem $31,25 \%$ de sua área ocupada pela agricultura familiar e também quanto ao Brasil, em que a agricultura familiar ocupa somente $24,01 \%$ das terras, mesmo representando $84,36 \%$ dos estabelecimentos agropecuários.

Assim, nota-se que uma das particularidades do Vale do Rio Pardo está não apenas no fato de seu território ser eminentemente rural e por sua população residir majoritariamente no campo, mas no número de estabelecimentos da agricultura familiar existentes nessa região e a porcentagem da área ocupada pelos mesmos.

Já o aspecto universal dessa região fica por conta da relação estabelecida com o SIPT, dada a importância dessa cultura e do arranjo produtivo estabelecido ao longo de quase um século. Atualmente, o Brasil é o maior exportador de fumo ${ }^{5}$ em folha do mundo e ocupa a

por organizações ligadas ao aparato estatal, com escasso envolvimento de outros atores, a nova abordagem de desenvolvimento regional recomenda ações concebidas "de baixo para cima", envolvendo a participação conjunta de atores públicos, privados e da sociedade civil, ações essas que devem ser específicas para cada região e que devem visar o longo prazo.

4 Veiga (2002) propõe outros critérios para a definição entre espaço rural e urbano. Segundo o autor, considerando como critérios de ruralidade a localização dos municípios, o tamanho da sua população e a sua densidade demográfica, entre os 5.560 municípios brasileiros, 4.490 deveriam ser classificados como rurais, sendo que a população rural corresponderia a, praticamente, o dobro da oficialmente divulgada pelo IBGE, atingindo $42 \%$ da população do país.

5 Tabaco e fumo são utilizados como sinônimos neste estudo. O tabaco é uma planta cujo nome científico é Nicotiana tabacum, da qual é extraída uma substância de efeito 
segunda colocação em produção, ficando somente atrás da China. Na safra $2012^{6}$, foram produzidas 726.770 toneladas de tabaco, gerando um faturamento total de mais de $\mathrm{R} \$ 22$ bilhões de reais e envolvendo 180 mil famílias produtoras, sendo a região Sul responsável por 97,38\% da produção brasileira. Já o Vale do Rio Pardo foi responsável por $19,92 \%$ do fumo em folha produzido em todo o Brasil no período de 2008 a 2012 , o que equivale a $39,89 \%$ da produção gaúcha.

O que se observa no Vale do Rio Pardo é a manutenção de um sistema muito bem articulado, econômica e politicamente, de defesa da cadeia produtiva do tabaco e constantes investimentos por parte do setor. Conforme Silveira e Dornelles (2013),

\begin{abstract}
os constantes investimentos das corporações transnacionais realizadas na modernização e na ampliação das plantas agroindustriais e nas fábricas de cigarros, localizadas no Sul do Brasil, têm permitido ao setor fumageiro manter-se atualizado em termos de capacidade produtiva e tecnológica para atender à demanda do mercado mundial de tabaco, afirmando assim sua condição de liderança (SILVEIRA e DORNELLES, 2013, p. 27).
\end{abstract}

Na pesquisa intitulada "Rede agroindustrial do fumo e a dinâmica de organização espacial e de usos do território na região Sul do Brasil", Silveira (2011) revela que, num contexto de expansão do capital agroindustrial de tabaco nos últimos 15 anos, a região Sul do Brasil não apenas manteve-se valorizada como fortaleceu sua condição de lugar estratégico na produção e na comercialização de tabaco em folha no âmbito mundial.

As condições ambientais diferenciadas favoráveis ao cultivo das principais variedades de sementes de tabaco, o conhecimento tácito, entre os agricultores, do cultivo de tabaco, a elevada qualidade e o baixo custo de produção do tabaco brasileiro decorrente do emprego da mão de obra familiar, o crescente aperfeiçoamento tecnológico do seu modo de produção e de

estimulante chamada nicotina. Além dessa, o tabaco possui mais de 4.700 substâncias. O tabaco pode ser usado de diferentes formas: inalado por meio de cigarro, charuto, cigarro de palha e cachimbo; aspirado por meio de rapé; mascado por meio de fumo-de-rolo. Todas as formas de consumo geram algum tipo de prejuízo ao organismo do usuário. (BRASIL, 2014.)

${ }^{6}$ AFUBRA (2014). 
processamento e a intensa regulação das relações de produção através do sistema integrado de produção são atributos territoriais que continuaram pesando na escolha da região. (SILVEIRA, 2011, p. 155)

No entanto, na medida em que essa cultura agrícola se torna a única alternativa de produção e de comercialização, tende a gerar dependência. Além disso, outros conhecidos prejuízos oriundos da produção de tabaco incluem a mão de obra intensa, o uso de uma quantidade considerável de agrotóxicos, gerando riscos à saúde e danos ao meio ambiente, além do endividamento dos agricultores familiares junto às empresas (VARGAS, 2013).

Conterato (2013), em recente trabalho, utiliza o Índice de Desenvolvimento Rural - IDR7 para verificar a existência de diferentes níveis de desenvolvimento entre regiões fumicultoras e não fumicultoras do Rio Grande do Sul. A pesquisa constatou que a produção de tabaco concentra-se nas regiões de desenvolvimento rural médio e baixo. Ainda, considerando que, no período analisado (2000 a 2008), tenha havido um aumento na área plantada com tabaco em todas as regiões, onde houve aumento mais significativo de novas áreas fumicultoras foi nas regiões com IDR Extremamente Baixo. E, em conjunto, as regiões de IDR Extremamente Baixo, Baixo e Médio correspondem a, aproximadamente, $86 \%$ da área plantada total com tabaco no Rio Grande do Sul.

O autor afirma que as dinâmicas de desenvolvimento rural tendem a se vincular estreitamente com os estilos regionais assumidos pela agricultura, principalmente a de base familiar. Por isso, há que se considerar a forte relação entre as formas de existência da agricultura familiar e as configurações regionais do desenvolvimento rural, revelando que "regiões mais desenvolvidas tendem a apresentar uma

\footnotetext{
7 Para a construção do IDR foram utilizados 36 indicadores distribuídos em cinco dimensões da seguinte forma: 8 na dimensão social, 6 da demográfica, 5 na políticoinstitucional, 12 na econômica e 5 na ambiental. Para efeitos de comparação entre as regiões, definiu-se a seguinte tipologia, considerando os valores mínimo e máximo entre 0 e 1: microrregiões de IDR Extremamente Baixo (quando IDR era inferior a 0,449); microrregiões de IDR Baixo (quando IDR variava entre 0,450 e 0,499); microrregiões de IDR Médio (quando IDR variava entre 0,500 e 0,549); microrregiões de IDR Médio-Alto (quando IDR variava entre 0,550 e 0,599) e; microrregiões de IDR Alto (quando IDR era superior a 0,600). (CONTERATO, 2013).
} 
agricultura familiar mais pujante, ao passo que, em regiões menos desenvolvidas, a agricultura familiar tende a ser mais vulnerável social e economicamente" (CONTERATO, 2013, p. 60).

Importante ainda é lembrar, nas palavras de Kageyama (2008), que o desenvolvimento rural não é identificado com desenvolvimento econômico, mas um processo que envolve múltiplas dimensões: dimensão econômica, dimensão sociocultural, dimensão políticoinstitucional e dimensão ambiental.

Eis a complexa relação do Vale do Rio Pardo com a cadeia produtiva do tabaco. Ao mesmo tempo em que números exorbitantes movimentam as exportações e inegavelmente toda a economia regional, estadual e até do país, o sistema integrado de produção tem gerado um vínculo de dependência entre ambos os lados - indústria e agricultores familiares. Se as empresas dependem da qualificada mão de obra familiar e das condições climáticas da região para produzir um tabaco de reconhecida qualidade internacional, assim também os produtores encontram-se dependentes e, em muitos casos, endividados. Uma situação paradigmática, que merece ser analisada e, no mínimo, provocar debates qualificados e imparciais na busca de um processo de diversificação produtiva que contraponha a dependência.

\section{A CRISE, OS MEDIADORES E A CRIAÇÃO DA COOPERLAF}

A pesquisa de campo que embasa este artigo foi realizada com 20 integrantes da COOPERLAF, entre os meses de agosto e novembro de 2013. As técnicas de coleta de dados utilizadas foram uma entrevista semiestruturada e um formulário, aplicadas durante visitas realizadas às propriedades. Dentre os entrevistados, 16 são agricultores familiares, produtores de alimentos e fornecedores do PAA e do PNAE, identificados ao longo da análise como cooperados. Além desses, entrevistou-se quatro membros da cooperativa, denominados a seguir de cooperados mediadores, em função do destacado papel de liderança e de mediação social realizado por eles, bem como pelo fato dos mesmos possuírem outra atividade profissional, não vivendo, portanto, exclusivamente da agricultura familiar.

Os dados foram trabalhados através da análise de conteúdo, iniciando-se pela transcrição literal das entrevistas e pela pré-análise 
das informações. Depois de uma leitura minuciosa, com base nas questões propostas pela pesquisa, fez-se a classificação das informações, de acordo com o seu conteúdo, em diferentes categorias explicativas da realidade para, finalmente, realizar-se a interpretação e a síntese dos resultados.

Esta pesquisa apoiou-se em uma compreensão dialética da realidade, considerando que "os fatos sociais não podem ser entendidos quando considerados isoladamente, abstraídos de suas influências políticas, econômicas, sociais, culturais, etc." (GIL, 2008, p14). Dessa forma, para compreender o processo de criação da COOPERLAF, consideraram-se alguns aspectos importantes relativos ao contexto geral do Vale do Rio Pardo, na época do surgimento da cooperativa, assim como a existência de elementos internos ao processo que também se mostraram determinantes.

Depois da ratificação, pelo senado brasileiro, da ConvençãoQuadro para o Controle do Tabaco - CQCT, em 2005, o debate sobre o futuro deste cultivo, assim como de toda a região dependente dela, tornou-se bastante acirrado. De um lado, uma postura de incerteza e de reivindicações foi assumida pelas entidades e pelas organizações mais comprometidas com a cadeia agroindustrial do tabaco, muitas delas prevendo repercussões negativas.

De outro, multiplicaram-se os debates em torno de programas que pudessem conduzir a agricultura familiar e a região a um patamar de maior autonomia. A própria CQCT, em seus artigos 17 e 18, determina que os países participantes promovam alternativas de produção, economicamente viáveis e ambientalmente sustentáveis, aos produtores de fumo. No caso do governo brasileiro, foi criado o Programa Nacional de Diversificação em Áreas Cultivadas com Tabaco PNDACT, coordenado pelo Ministério do Desenvolvimento Agrário MDA, que desenvolve ações nos âmbitos mundial e nacional e nas regiões produtoras de fumo no Brasil.

Além do PNDACT, lançado em 2005, as secretarias de agricultura dos municípios, bem como a EMATER e outras entidades sindicais e movimentos sociais passaram a desenvolver projetos de diversificação. Foi o caso do Município de Boqueirão do Leão que, no ano de 2007, começou a projetar uma série de ações nesse âmbito, que culminaram, em 2010, com a promulgação da Lei Municipal $n^{\circ} 1284$, que consolidou 
o Programa de Diversificação da Agricultura Familiar, bem como o Programa de subsídio de sementes e o Programa de incentivo à produção leiteira.

Outro movimento realizado na região, no sentido da reflexão sobre o desenvolvimento regional, foi conduzido pelo Programa Territórios da Cidadania, do Ministério de Desenvolvimento Agrário $(\text { SDT } / M D A)^{8}$, e teve participação ativa de técnicos e de lideranças do Município de Boqueirão do Leão e do escritório municipal da EMATER. Esse debate acabou gerando um Plano Territorial de Desenvolvimento Rural Sustentável, cuja construção ocorreu entre janeiro de 2009 e fevereiro de 2011 e resultou na formação do Pré-território do Pinhão e da Erva Mate9. Dentre os objetivos descritos no plano estavam: a articulação das entidades ligadas ao meio rural; a formação/capacitação de agricultores e técnicos dos municípios; o aumento da rede de assistência técnica; e o fortalecimento das cadeias produtivas potenciais existentes no território.

Para completar esse contexto político-econômico-institucional que, de acordo com os resultados da pesquisa, serviu de base para a criação da COOPERLAF, faz-se necessário um destaque à emergência do mercado institucional de alimentos. A obrigação legal, determinada pelo PNAE por intermédio da Lei $n^{0} 11.947 / 09$, da utilização de $30 \%$, ao menos, do recurso da merenda escolar para aquisição de alimentos da agricultura familiar, efetivamente, constituiu-se em uma possibilidade

8 O Programa Territórios da Cidadania tem por base outro programa, o Programa Desenvolvimento Sustentável de Territórios Rurais (PRONAT) e conta com a parceria de diversas instituições da sociedade civil, nos governos federal, estaduais e municipais. O PRONAT começou a operar em 2004 em 65 territórios. Em 2006, abrangia 118 e, atualmente, conta com 164 territórios rurais compostos por 2,5 mil municípios. Deste total, 120 foram incorporados ao Programa Territórios da Cidadania, criado pelo governo federal em 2008 e coordenado pela Casa Civil da Presidência da República. A SDT atua nos territórios apoiando a organização e o fortalecimento institucional dos atores sociais locais na gestão participativa (MDA, 2014).

9 Esse pré-território reuniu 14 municípios, sendo que não acompanhou a regionalização dos Coredes, por levar em conta outros fatores de identidade cultural, de produção e condições socioeconômicas. Dessa forma, teve em sua configuração, a sobreposição de três Coredes (Vale do Taquari, Alto da Serra do Botucaraí e Vale do Rio Pardo). Os municípios membros do Pré-Território do Pinhão e da Erva Mate são: Itapuca, Arvorezinha, Ilópolis, Putinga, Fontoura Xavier, São José do Herval, Pouso Novo, Marques de Souza, Barros Cassal, Progresso, Boqueirão do Leão, Gramada Xavier, Herveiras e Sinimbu. 
concreta de mercado garantido e regular para os agricultores familiares. A experiência de produção e de venda de alimentos para a merenda escolar em Boqueirão do Leão acabou constituindo um grupo informal de produção, articulado pela Empresa de Assistência Técnica e Extensão Rural - EMATER e, logo em seguida, veio a ser o elemento propulsor do início da COOPERLAF.

Assim, fica claro que a COOPERLAF surge da oportunidade de comercialização de alimentos para o mercado institucional, no caso, o PNAE, mas, principalmente, incentivada por um contexto de crise, ou de instabilidade do paradigma do tabaco, e de uma busca por alternativas.

Percebe-se que as propostas ligadas ao mercado institucional de alimentos, por meio do PAA e do PNAE, são apresentadas como base de um outro modelo de desenvolvimento, diferente daquele pautado pelo agronegócio que também sustenta a cadeia agroindustrial do tabaco. $\mathrm{Na}$ contramão da dependência de insumos, de sementes e do capital internacional, a diversificação produtiva proposta pelo PAA e pelo PNAE propõe-se a conectar a oferta da produção familiar a uma demanda garantida e permanente, assim como fortalecer os circuitos locais e regionais e as redes de comercialização, valorizar a biodiversidade, a produção orgânica e agroecológica de alimentos, incentivar hábitos alimentares saudáveis e estimular o cooperativismo.

Considerar, portanto, que a COOPERLAF se origina de uma proposta ideologicamente pautada pela renovação do projeto de desenvolvimento vigente na região, é fundamental para compreender suas características, objetivos e resultados, pois, de um modo geral, o que se identificou, ao longo da pesquisa com os cooperados, foi justamente a as contradições existentes entre estes dois diferentes projetos de desenvolvimento: a dependente integração produtiva à rede agroindustrial do tabaco e a agricultura familiar autônoma, sustentável, impulsionada pela produção de alimentos para o mercado institucional.

Mas, além do conjunto de fatores de ordem macro social, econômica, política e institucional apresentados, as entrevistas com os agricultores cooperados evidenciaram a existência de elementos internos ao processo de criação da COOPERLAF que interferiram decisivamente em sua constituição. Trata-se do trabalho de mediação social realizado por dois técnicos em agropecuária ligados à Secretaria Municipal de Agricultura de Boqueirão do Leão e ao Escritório Municipal 
da EMATER/ASCAR. A análise da pesquisa demonstrou que os mesmos exerceram uma função essencial na mediação entre os agricultores familiares e as políticas públicas existentes. Inclusive, ambos tornaramse sócios fundadores da COOPERLAF, ultrapassando os limites habituais da extensão rural, geralmente apenas repassadora de informações técnicas. Por isso, esses profissionais foram chamados, nesta análise, de cooperados mediadores.

As evidências do envolvimento direto e decisivo dos cooperados mediadores no processo de constituição da COOPERLAF podem ser observadas no relato dos agricultores ao responderem sobre o início da cooperativa.

\begin{abstract}
A cooperativa surgiu de uma necessidade de se organizar para viabilizar aquela vontade de que a agricultura familiar produzisse o seu próprio alimento e até fornecesse para a merenda escolar que veio forte. Tinha alguns produtores que forneciam pelo talão de produtor, mas aí tinha aquela questão mais burocrática e então o Leandro e a Celita começaram a trabalhar a hipótese de se formar uma cooperativa, de organizar, de juntar esses produtores, de potencializar isso, de todos falarem a mesma língua. (C.1)

Começou eu e o Alpídio. Eu vendia salame e o Alpídio vendia verdura, ovos, queijo. Aí precisava pra merenda escolar os municípios precisavam comprar $30 \%$ da agricultura familiar, aí começou por ali. Nós fomos conversando, o Lesndro e a Celita vieram aqui pra falar e aí foi surgindo. (C. 11).
\end{abstract}

Percebe-se, em ambas as falas, a função mediadora dos técnicos. O primeiro depoimento refere que os cooperados mediadores "começaram a trabalhar a hipótese de se formar uma cooperativa...", e o segundo diz que eles "vieram aqui pra falar". Ou seja, a criação da COOPERLAF se fez por meio de um processo de articulação dos agricultores e de diálogo sobre as possibilidades de uma ação conjunta, cooperada.

A mediação social é uma categoria teórico-analítica referenciada por diversos autores que estudam os processos sociais, especialmente aqueles vinculados a projetos de desenvolvimento. Segundo Neves (2008), recentemente os termos mediação e mediador têm sido valorizados como qualificação de modalidades de prestação de serviços, 
ou como método de intervenção social. O mediador normalmente é entendido como o agente responsável por intervir em divergências e propor acordos entre as partes. Nesse sentido, a autora traz uma forte crítica às formas de mediação técnica e de prestação de serviços existentes em processos que envolvem a reordenação social e a constituição de novos modos de comportamento ou de formas de percepção e de representação do mundo.

A crítica ressalta o caráter de unilateralidade que pode haver nos processos de mediação social, em que o mediador impõe suas verdades diante dos mediados. Nesse sentido, Ros (2008) defende uma análise sobre o tipo de vínculo criado entre mediadores e mediados. Segundo esse autor, é preciso considerar não apenas a estratégia de intervenção dos primeiros, mas a interação que se estabelece entre as partes intervenientes. As análises sobre a mediação social devem, portanto, contribuir para superar esse obstáculo, interpretando o vínculo como uma relação de troca, na qual se intercambiam bens materiais e/ou simbólicos, tal como se observa no depoimento abaixo.

Eu comecei porque a Celita e o Leandro me convidaram. A gente já se conhecia há tempo. Quando o Leandro começou aqui no município, eu era secretária do Clube de Mães e a gente tinha uma carência muito grande de um trabalho com as mulheres em relação ao aproveitamento dos alimentos, das frutas que tem na comunidade. E o Leandro é um técnico agrícola, mas tem muito esse perfil de trabalhar o social. Então a gente trabalhou essa questão das plantas medicinais, horta, trabalhamos o aproveitamento de alimentos. Então a gente se conheceu e a gente tem muita afinidade porque a gente pensa muito parecido (C.1).

Seguindo a análise sobre a atuação dos cooperados mediadores, observa-se que, em pouco tempo, um considerável volume de recursos públicos foi destinado à COOPERLAF por meio de projetos, tanto em nível estadual quanto federal. Por intermédio do Pré-território do Pinhão e da Erva Mate, a prefeitura municipal de Boqueirão do Leão conseguiu canalizar recursos do MDA para a compra de equipamentos e de veículos a serem utilizados na organização da produção e na distribuição de alimentos, tendo o trabalho da COOPERLAF como justificativa do projeto. Foram adquiridos um caminhão (com baú 
refrigerado) e uma caminhoneta para transporte dos produtos, além de uma câmara fria de $25 \mathrm{~m}^{2}$. Posteriormente, estes bens foram repassados pela prefeitura para a COOPERLAF por meio de um comodato (Lei Municipal $n^{0} 1396$, de 10 de dezembro de 2012) e possibilitaram uma nova dinâmica de produção e de entrega dos produtos pela cooperativa, tanto para a merenda escolar (PNAE) quanto para o PAA.

Acredita-se que, nesse caso, a atuação dos cooperados mediadores também tenha sido decisiva. Tanto a elaboração técnica dos projetos quanto a articulação política necessária para encaminhá-los e aprová-los não fazem parte das habilidades dos agricultores familiares integrantes da cooperativa. Dessa forma, embora a COOPERLAF se enquadre no perfil de entidade a ser atendida pelas políticas públicas destinadas especificamente à produção de alimentos pela agricultura familiar, os agricultores sozinhos, sem o trabalho dos técnicos, teriam muita dificuldade para atender às exigências burocráticas e 0 conhecimento técnico exigido para aprovação das propostas.

Nesse sentido, destaca-se que a COOPERLAF, já no seu primeiro ano de funcionamento (2011-2012), realizou o primeiro projeto do PAA do município de Boqueirão do Leão, fornecendo, pelo período de um ano, cestas mensais de alimentos da agricultura familiar para 360 famílias em situação de vulnerabilidade social, por meio da modalidade Compra com Doação Simultânea.

Pelo PNAE, a COOPERLAF passou a fornecer alimentos para a merenda escolar oficialmente no segundo semestre de 2011 , atingindo um valor de $R \$ 25.751,53$. Nesse ano, o grupo informal também continuou fornecendo, chegando ao montante de $R \$ 20.598,92$. Assim, em 2011, somados os valores da COOPERLAF com o grupo informal, o Município de Boqueirão do Leão utilizou $80 \%$ do recurso do Fundo Nacional de Desenvolvimento da Educação - FNDE (considerando que a exigência legal é de 30\%). Já no ano de 2012, o valor comercializado pela COOPERLAF por meio do PNAE atingiu $R \$ 45.794,20$, equivalente a $100 \%$ do recurso do FNDE, mais $\mathrm{R} \$ 5.190,00$ de recursos próprios do município.

Além do fornecimento da alimentação escolar para as escolas municipais, a COOPERLAF também comercializou sua produção diretamente para as escolas estaduais que funcionam em Boqueirão do 
Leão, atingindo $R \$ 74.355,92$ em $2011, \mathrm{R} \$ 77.076,25$ em 2012 e $\mathrm{R} \$$ 76.190,00 em 2013.

Esses números demonstram o potencial de comercialização existente por meio do mercado institucional, bem como o importante trabalho de articulação realizado pela COOPERLAF, tanto em relação à elaboração dos projetos como para a produção e para entrega desses produtos. Porém, a pesquisa não conseguiu determinar com precisão os valores correspondentes às vendas individuais dos agricultores cooperados, no sentido de verificar a sua renda anual proveniente da comercialização via cooperativa e, com isso, a sua capacidade de diminuir a dependência do cultivo de tabaco.

Porém, é possível realizar um cálculo de âmbito geral, tendo por base o ano de 2012, em que somados os valores do PAA $(\mathrm{R} \$ 106.000,00)$ e do PNAE $(\mathrm{R} \$ 128.060,00)$ e dividindo pelo número de 24 cooperados fornecedores nesse mesmo ano ${ }^{10}$, chega-se a uma renda média anual de $R \$ 9.752,00$, que é bastante significativa.

A análise desses valores também sugere uma opção política realizada pela gestão municipal da época, pois se realizou a compra de alimentos da agricultura familiar para a merenda escolar em percentuais muito superiores aos exigidos por lei. Assim também pode-se dizer em relação ao PAA, que, por intermédio da COOPERLAF, garantiu o fornecimento mensal de alimentos da agricultura familiar para 360 famílias em situação de insegurança alimentar, unindo a política pública de Assistência Social a um novo mercado para os agricultores.

\section{4 "PORQUE AGORA A GENTE TEM ONDE VENDER NÉ": A COOPERLAF E SEUS RESULTADOS}

Como se observa nos relatos desses cooperados, o surgimento do mercado institucional de alimentos trouxe confiança e novas perspectivas produtivas aos agricultores familiares.

Porque agora a gente tem onde vender né. Já aconteceu de colher 20, 25 sacos de feijão e apodrecer quase tudo, botar

\footnotetext{
10 Nota-se que nem todos os cooperados, que somam 41 no total, fornecem produtos para a cooperativa. Observou-se que muitos se associaram no intuito de comercializar o excedente de sua produção para subsistência familiar, em geral agricultores aposentados que enxergaram na cooperativa uma possibilidade de renda extra.
} 
fora, porque não tinha onde vender. Hoje não, hoje até falta. Nós colhemos 15 sacos e eu tirei 126 quilos pro consumo e não vai chegar, vai faltar feijão. (C6)

A diversificação de produção, que antes era mais para consumo, hoje está também voltada para a venda (...) Antes da cooperativa nós não vendíamos muita coisa, um pouco de milho e um pouco de mel. As frutas por exemplo caiam tudo do pés. Quando vinha alguém a gente dava de presente. (C 13)

Quanto à comercialização dos produtos, constatou-se que, além da venda para o mercado institucional por intermédio da cooperativa, muitos realizam venda-direta. Dos 16 entrevistados, 11 declararam que vendem seus produtos diretamente para os consumidores, na feira-livre do município, por intermédio de comércio ambulante (inclusive no meio rural) ou diretamente para clientes que visitam suas propriedades em busca de seus produtos. Essa situação demonstra que não está ocorrendo um processo de dependência em relação ao mercado institucional, sendo que os agricultores cooperados utilizam outros canais de comercialização dos alimentos produzidos, além do PAA e PNAE.

Hoje a gente entrega pra cooperativa 60 dúzias de ovos por mês e o resto eu vendo direto pro consumidor. Até nós estamos querendo aumentar o número de galinhas. Porque falta ovos, o pessoal vem buscar em casa. (C8)

Eu passo nos lugar e vou vendendo nas casas. No comércio não vale a pena, porque eles pagam muito pouco. O negócio é vender direto. Aí eu já tenho encomenda, passo só nos lugares onde eu já vendi e não consigo nem atender a todos. (C15)

Observou-se também que o acesso ao mercado institucional despertou um potencial antes não explorado efetivamente por estes agricultores. Na medida em que passaram a produzir alimentos com o objetivo de vender para o PAA e para o PNAE, descobriram também a oportunidade da venda direta, estabelecendo um novo processo produtivo, além da produção e venda de tabaco. O que se observou pelos relatos nas entrevistas foi o surgimento de uma nova identidade por parte destes, que não se enxergam mais apenas como fumicultores 
ou produtores de tabaco, mas como agricultores familiares produtores de alimentos.

\section{ENTRE A DEPENDÊNCIA DO IMPÉRIO E A AUTONOMIA DA SAN: A CAMINHO DA RECAMPESINIZAÇÃO?}

Como já se demonstrou, o mercado institucional de alimentos por meio do PAA e o do PNAE ancora-se no conceito das políticas de SAN, que segundo Maluf (2011), objetivam aproximar produtores e consumidores, a fim de proporcionar a aquisição de alimentos saudáveis, com menor grau de processamento e a diversificação dos hábitos de consumo. Além disso, o mercado institucional, ao apoiar os circuitos regionais de produção e de distribuição de alimentos, pretende promover o desenvolvimento rural ou territorial, com ênfase na geração de trabalho e de renda para os agricultores familiares (MALUF, 2011).

Portanto, o conceito de SAN está diretamente relacionada a um modelo de agricultura que garanta não apenas a produção de alimentos e o seu acesso por parte da população em situação de vulnerabilidade, mas a qualidade destes alimentos. Por isso, a política de SAN coloca-se em oposição a uma agricultura globalizada, sob o controle das grandes corporações transnacionais, e reforça o fortalecimento de uma agricultura de base familiar, alicerçada no uso múltiplo dos recursos naturais e no potencial endógeno das comunidades (SCHMITT, 2013).

Esse enfoque se mostra convergente com a abordagem desenvolvida por Ploeg $(2006,2008)$, que coloca a agricultura camponesa e os processos de recampesinização como alternativa ao modelo dos Impérios Alimentares. Para esSe autor, "o Império é uma estrutura composta por esquemas reguladores, de natureza política e econômica, que são impostos à sociedade e à natureza" (PLOEG, 2008, p. 279). Ainda nas palavras de Ploeg (2008), o Império consiste na combinação histórica e contraditória, mas sistemática, de dois princípios orientadores: o mercado global e o sistema de linha de montagem. As chamadas cadeias alimentares seriam, assim, a combinação desses dois princípios. O núcleo do Império é representado por um conjunto de normas e de parâmetros generalizados que são fruto da atual fase da globalização. Dessa forma, os espaços que antes eram autogovernados 
ou autônomos são conquistados pelo Império, que os transforma em um "não lugar".

Assim, por meio do processo de industrialização, os Impérios alimentares acarretam em uma desconexão definitiva entre produção e consumo, bem como uma modificação do tempo e do espaço na produção dos alimentos. A industrialização permite o processamento de alimentos produzidos em um determinado local, transformando-os em produtos que podem ser consumidos onde quer que seja e com prazo de validade muito ampliado. Com isso, o processo de produção agrícola, antes orgânico e regulado pela natureza, passa a ser controlado e artificializado.

Nessa mesma linha de reflexão, Norder (2009, p. 63) afirma que, diante da industrialização da agricultura, houve uma

\footnotetext{
crescente desconexão entre a produção agropecuária e as condições locais como a natureza e a ecologia, as peculiaridades da força de trabalho, a elaboração de produtos com características culturais e regionais específicas e a organização de formas autônomas de organização do trabalho.
}

Essa desconexão, característica da modernização agrícola, para Norder (2009), resultou nos processos de mercantilização, acentuada utilização de insumos de origem agroindustrial e forte dependência em relação a agentes externos, o que provocou e continua provocando modificações nas condições de produção da agricultura familiar.

Em contrapartida, Ploeg $(2009 ; 2008)$ defende a existência de relevantes processos de recampesinização nos dias de hoje. Conforme o autor, "Recampesinização é, de fato, a segunda importante tendência histórica que moveu o mundo rural para além do clássico dualismo entre capitalistas e camponeses" (PLOEG, 2009, p. 19). Segue ainda explicando que o "camponês" não é mais o lado da equação que vai desaparecendo e que "a recampesinização expressa a formação de novas, de robustas e de promissoras constelações - que se apresentam, cada vez mais, superiores aos demais modos de produção" (PLOEG, 2009, p. 19).

A recampesinização consiste em um processo com dois movimentos. O primeiro é o aumento quantitativo no número de camponeses por meio de uma reconversão, por exemplo, de 
agricultores empresariais em camponeses. O segundo seria uma mudança qualitativa na qual a autonomia é aumentada e há um alargamento da base de recursos antes reduzida pelos processos de especialização, gerando uma diminuição da dependência em relação aos mercados (PLOEG, 2008).

A unidade camponesa de produção, segundo Ploeg (2006, p. 23),

é precisamente a forma institucional que distancia a atividade agropecuária, de maneira específica e estrategicamente organizada, do mercado (de insumos), ao mesmo tempo em que a vincula (também de maneira específica e estrategicamente organizada) a outros mercados (de produtos).

Nesses termos, se o estilo camponês de agricultura familiar representa uma alternativa ao Império e à industrialização, pode-se entender que o mesmo estaria mais adequado à proposta dos mercados institucionais, pautada no conceito de SAN. Assim, seria possível afirmar que a operacionalização do mercado institucional de alimentos pautado pelo conceito de SAN, com objetivo de incentivar as cadeias curtas de alimentos, a produção orgânica e a autonomia dos agricultores familiares - estaria favorecendo um processo de recampesinização da agricultura familiar?

\section{CONSIDERAÇÕES FINAIS}

Viu-se que o Vale do Rio Pardo, enquanto região ancorada na produção de tabaco, enfrenta a necessidade de uma ressignificação de seu processo de desenvolvimento. Principalmente depois da ratificação da CQCT, surgiram dúvidas e insegurança quanto às garantias e facilidades geradas pelo SIPT, evidenciando um importante grau de dependência regional frente a esta cultura.

Entende-se que as alternativas devem considerar as particularidades dessa região, principalmente no que se refere à agricultura familiar. Nesse sentido, a produção de alimentos se mostra um caminho em potencial, principalmente se vinculada às políticas públicas de SAN.

A experiência da COOPERLAF, embora inicial e por isso frágil no sentido de gerar conclusões, mostra-se extremamente valiosa por seu 
caráter inovador e pioneiro. Fruto da articulação de seus cooperados mediadores e do trabalho dos agricultores familiares, esta cooperativa, em pouco tempo de existência, comprovou o potencial e a importância de políticas públicas como o PAA e o PNAE.

É preciso atentar para o fato de que as políticas de SAN apresentam uma abordagem conceitual diferente daquela que embasa $\mathrm{O}$ SIPT e o modelo de desenvolvimento agrícola hegemônico. Por isso a dificuldade de serem compreendidas e executadas. Não fosse assim, outras experiências como a da COOPERLAF estariam sendo realizadas em todos os municípios da região.

Por fim, sabe-se das limitações desta pesquisa em termos de análise generalizada quanto à operacionalização do mercado institucional de alimentos no Vale do Rio Pardo. Por isso, propõe-se que, assim como a COOPERLAF, outros grupos de agricultores familiares sejam ouvidos sobre as suas experiências de inserção no mercado institucional de alimentos. Certamente, o prosseguimento das investigações sobre esta temática traria importantes resultados para embasar os processos de avaliação e de planejamento quanto aos rumos do desenvolvimento dessa região.

\section{REFERÊNCIAS}

AFUBRA. ASSOCIAÇÃO DOS FUMICULTORES DO BRASIL. Apresenta informações gerais sobre a instituição e sobre a fumicultura. Disponível em: <www.afubra.com.br>. Acesso em: 10 jan. 2014.

BANDEIRA, P. S. Contribuição dos COREDEs/RS para o debate sobre a Política nacional de desenvolvimento regional. In: SILVEIRA, R. L. L. (Org.). Observando o desenvolvimento regional brasileiro: processo, políticas e planejamento [recurso eletrônico]. Santa Cruz do Sul: EDUNISC, 2013. Disponível em: <www.unisc.br/edunisc > Acesso em: 08 mar. 2014.

BIALOSKORSKI NETO, Sigismundo. Governança e Perspectivas do Cooperativismo. I Workshop Internacional de Tendências do Cooperativismo, 1998, Ribeirão Preto. Anais, 1998. 
CONTERATO, Marcelo Antonio. Desenvolvimento rural desigual: uma análise entre microregiões fumicultoras e não fumicultoras no Rio Grande do Sul. In: SILVEIRA, R.L.L.(Org.). Tabaco, sociedade e território: relações e contradições no Sul do Brasil. Santa Cruz do Sul: EDUNISC, 2013.

CORRÊA, Roberto Lobato. Região: A tradição geográfica. In: Trajetórias Geográficas. Rio de Janeiro: Bertrand Brasil, 1997.

GIL, Antônio Carlos. Como Elaborar Projetos de Pesquisa. 4 ed. São Paulo: Atlas, 2002.

GIL, Antonio Carlos. Métodos e Técnicas de Pesquisa Social. São Paulo: Atlas, $2011.6^{\mathrm{a}}$ ed.

IBGE. INSITUTO BRASILEIRO DE GEOGRAFIA E ESTATÍ́STICA. Produção Agrícola Municipal, 2012.2 Disponível em: $<$ http://www.sidra.ibge.gov.br/bda/pesquisas /pam /default.asp?o=18\&i $=P>$. Acesso em: 10 jan. 2014.

KAGEYAMA, Angela. Desenvolvimento Rural: conceitos e aplicações ao caso brasileiro. Porto Alegre: Editora da UFRGS, 2008.

MALUF, Renato S. Segurança Alimentar e Nutricional. Petrópolis, RJ: Vozes, 2011.

NEVES, Delma Pessanha. Mediação social e mediadores políticos. In: NEVES, D. P. (Org.). Desenvolvimento social e mediadores políticos. Porto Alegre: Editora da UFRGS: Programa de Pós Graduação em Desenvolvimento Rural, 2008.

NIEDERLE, Paulo André (Org.). Indicações Geográficas: qualidade e origem nos mercados agroalimentares. Porto Alegre: Editora da UFRGS, 2013.

NIEDERLE, Paulo André. Mercantilização, estilos de agricultura e estratégias de reprodução dos agricultores familiares de Salvador das 
Missões - RS. Dissertação, 218 f. Programa de Pós Graduação em Desenvolvimento Rural - UFRGS. Porto Alegre, 2007.

NORDER, Luiz Antonio C. Mercantilização da agricultura $e$ desenvolvimento territorial. In: SCHNEIDER, S. (Org.). A diversidade da agricultura familiar. 2. ed. Porto Alegre, Editora da UFRGS, 2009. p. 5984.

PLOEG, J. D. Van der. Camponeses e impérios alimentares: lutas por autonomia e sustentabilidade na era da globalização. Tradução de Rita Pereira. Porto Alegre: Editora da UFRGS, 2008.

PLOEG, J. D. Van der. O modo camponês revisitado. In: SCHNEIDER, S. (Org.). A diversidade da agriculturafamiliar. 2. ed. Porto Alegre, Editora da UFRGS, 2009. p. 15-56.

ROS, Carlos Cowan. Mediação e conflito: lógicas de articulação entre agentes de promoção social e famílias camponesas, no norte da Província de Jujuy, Argentina. In: NEVES, D. P. (Org.). Desenvolvimento social e mediadores políticos. Porto Alegre: Editora da UFRGS: Programa de Pós Graduação em Desenvolvimento Rural, 2008.

SCHMITT, Claudia Job. Transição agroecologica e desenvolvimento rural: um olhar a partir da experiência brasileira. In: SAUER, S.; BALESTRO, M. V. (Org.). Agroecologia e os desafios da transisção agroecológica. São Paulo: Expressão Popular, 2013, 2. ed.

SCHNEIDER, S. (Org.). A diversidade da agricultura familiar. Porto Alegre: Editora da UFRGS, 2009. 2 ed.

SCHNEIDER, S. Agricultura familiar e desenvolvimento rural endógeno: elementos teóricos e um estudo de caso. In: Froehlich, J.M.; Vivien Diesel. (Org.). Desenvolvimento Rural - Tendências e debates comtemporâneos. ljuí: Unijuí, 2006.

SCHNEIDER, S; MATTEI, L; CAZELLA, A. A. Histórico, caracterização e dinâmica recente do PRONAF - Programa Nacional de Fortalecimento da 
Agricultura Familiar. In: SCHNEIDER, Sergio; SILVA, Marcelo Kunrath; MARQUES, Paulo Eduardo Moruzzi (Org.). Políticas Públicas e Participação Social no Brasil Rural. Porto Alegre, 2004, p. 21-50.

SILVEIRA, R. L. L. A experiência recente do planejamento regional no território do Vale do Rio Pardo RS: avanços, dificuldades e desafios. In: I Seminário de Desenvolvimento Regional, Estado e Sociedade, 2012, Rio de Janeiro-RJ. Anais do I Seminário de Desenvolvimento Regional, Estado e Sociedade. Rio de Janeiro: IPPUR-RJ, 2012. v. 01. p. 1-27.

SILVEIRA, R.L.L. (Org.) Rede agroindustrial do fumo e a dinâmica de organização espacial e de usos do território na região Sul do Brasil. Relatório Final de Pesquisa. Santa Cruz do Sul: CNPQ/UNISC, Janeiro, 2011.

SILVEIRA, R.L.L.; DORNELES, M. A produção de tabaco no sul do Brasil: um olhar geográfico sobre a sua dinâmica produtiva e organização territorial. In: SILVEIRA, R.L.L.(Org.). Tabaco, sociedade e território: relações e contradições no Sul do Brasil. Santa Cruz do Sul: EDUNISC, 2013. p. 17-38.

TEDESCO, J. C. (1999). Terra, Trabalho e família: racionalidade produtiva e ethos camponês. Passo Fundo: EDIUPF.

VARGAS, Marco Antonio. Cultivo do tabaco, agricultura familiar e estratégias de diversificação no Brasil: uma análise comparativa em áreas de cultivo de tabaco no Vale do Rio Pardo. In: SILVEIRA, R.L.L.(Org.). Tabaco, sociedade e território: relações e contradições no Sul do Brasil. Santa Cruz do Sul: EDUNISC, 2013. p. 123-156.

VEIGA, José Eli da. Cidades imaginárias: o Brasil é menos urbano do que se calcula. Campinas: Autores Associados, 2002. 
A operacionalização do Mercado Institucional de Alimentos no contexto do Vale do Rio

Pardo-RS

\section{Antônio Carlos Gomes}

Mestre em Desenvolvimento Regional pelo Programa de Pós-Graduação em

Desenvolvimento Regional - UNISC. Professor da Escola Família Agrícola de Santa Cruz do Sul.

E-mail: antoniogomesrs@hotmail.com

\section{Cidonea Machado Deponti}

Doutora em Desenvolvimento Rural pela Universidade Federal do Rio Grande do Sul. Docente do Programa de Pós-Graduação em Desenvolvimento Regional - UNISC.

Endereço: Av. Independência, 2293, Bloco 10, Sala 1021/06. 96815-900 - Santa Cruz do Sul - RS - Brasil.

E-mail: cidonea@unisc.br 